\title{
PENERAPAN KOMUNIKASI TERAPEUTIK TERHADAP STRES HOSPITALISASI PADA ANAK USIA TODDLER DI RUMAH SAKIT UMUM BAHTERAMAS
}

\author{
Siti Umrana ${ }^{1}$ Risnawati ${ }^{2}$ Aluddin ${ }^{3}$ \\ 1,2,3Program Studi DIII Keperawatan Akademi Keperawatan PPNI Kendari \\ sitiumrana82@gmail.com¹ risnausman81@gmail.com²Aluddin70@yahoo.com ${ }^{3}$
}

\begin{abstract}
Abstrak
Komunikasi yang kurang baik antara tenaga kesehatan dan pasien merupakan salah satu permasalahan terhadap pelayanan kesehatan. Kurangnya komunikasi antara petugas rumah sakit dan pasien sering terjadi ketidakpuasan akan kualitas dan jumlah informasi yang diterima pasien dari para petugas kesehatan di rumah sakit. Tujuan penelitian ini adalah untuk mengetahui hubungan penerapan komunikasi terapeutik dengan stres hospitalisasi pada anak usia toddler di Ruang Mawar Lantai 2 RSU Bahteramas Provinsi Sulawesi Tenggara. Penelitian ini adalah penelitian survey analitik. Sampel penelitian adalah pasien anak toddler yang dirawat di Ruang Mawar Lantai 2 RSU Bahteramas Provinsi Sulawesi Tenggara dengan jumlah sampel sebanyak 39 pasien yang diambil dengan teknik simple random sampling. Hasil penelitian menunjukkan bahwa fase pra interaksi, fase perkenalan, fase orientasi, fase kerja dan fase terminasi mempunyai hubungan yang signifikan dengan dengan stres hospitalisasi pada anak usia toddler di RSU Bahteramas. Senantiasa mempertahankan bahkan meningkatkan komunikasi terapeutik dalam memberikan pelayanan keperawatan kepada pasien.
\end{abstract}

Kata kunci: Komunikasi Terapeutik, Stres Hospitalisasi

\begin{abstract}
Poor communication between health workers and patients is one of the problems with health services. Lack of communication between hospital staff and patients often results in dissatisfaction with the quality and amount of information patients receive from hospital health workers. The purpose of this study was to determine the relationship between the application of therapeutic communication and hospitalization stress for toddlers in the Mawar Room, 2nd Floor of Bahteramas Hospital, Southeast Sulawesi Province. This research is an analytical survey research. The sample of this research was toddler child patients who were treated in the Mawar Room, 2nd Floor of Bahteramas Hospital, Southeast Sulawesi Province with a total sample of 39 patients who were taken using simple random sampling technique. The results showed that the pre-interaction phase, the introduction phase, the orientation phase, the work phase and the termination phase had a significant relationship with hospitalization stress for toddlers at Bahteramas Hospital. Always maintain and even improve therapeutic communication in providing nursing services to patients.
\end{abstract}

Keywords: Therapeutic Communication, Hospitalization Stress 


\section{PENDAHULUAN}

Kurangnya komunikasi antara staf rumah sakit dan pasien merupakan salah satu alasan keluhan umum pasien di rumah sakit. Keluhan pasien sering merasa tidak puas dengan kualitas dan jumlah informasi yang diterima dari petugas kesehatan di rumah sakit. Sekitar 35-40 \% pasien merasa tidak puas berkomunikasi dengan dokter dan perawat, disebabkan oleh aspek jumlah dan jenis informasi yang diterima ${ }^{1}$.

Kemampuan komunikasi telah didapatkan pada saat pendidikan keperawatan ataupun suatu pelatihan - pelatihan dalam bidang keperawatan. namun, masih saja terdapat perawat dengan komunikasi kurang baik, dikarenakan perawat mempunyai beberapa kendala dalam proses komunikasi dengan pasien dan keluarga seperti bahasa yang gunakan atau yang disampaikan kurang jelas atau bahasa yang susah dipahami dan dimengerti ${ }^{2}$

Hospitalisasi pada anak seringkali menjadikan anak dan orang tua mengalami pengalaman yang menimbulkan rasa stres yang berdampak pada perawatan anak selama di rumah sakit. Pada hospitalisasi anak cenderung mengalami kecemasan oleh karena takut dengan lingkungan rumah sakit, prosedur tindakan atau bahkan kematian, perpisahan, keterbatasan privasi, dan melakukan kegiatan rutinitas. Kebanyakan stres hospitalisasi yang banyak dikeluhkan oleh orang tua anak sebagai akibat dari kurangnya informasi yang diberikan oleh tenaga kesehatan tentang prosedur dan pengobatan, ketidaktahuan tentang aturan dan peraturan rumah sakit, rasa tidak diterima dan tidak diperhatikan oleh petugas kesehatan atau takut mengajukan pertanyaan serta orang tua merasa tidak dilibatkan dalam perawatan anak selama hospitalisasi Faktor stressor yang utama dan sering terjadi pada anak dengan hospitalisasi adalah perpisahan, kehilangan kontrol, trauma fisik dan nyeri, serta kondisi lingkungan rumah sakit ${ }^{3}$ (Wong, 2008). Berdasarkan reaksi yang ditimbulkan anak akibat hospitalisasi, pelayanan kesehatan meminimalkan dampak hospitalisasi memegang peranan penting dalam proses hospitalisasi agar anak mampu beradaptasi dengan lingkungan rumah sakit ${ }^{4}$.

Berdasarkan informasi dalam hal ketenagakerjaan di RSU Bahteramas khususnya di Ruang Mawar tahun 2017 tercatat sebanyak 19 orang tenaga perawat yang terdiri dari 1 orang $(5,26 \%) \quad$ Ners, 7 orang $(36,85 \%)$ Sarjana Keperawatan, 10 orang (52,63\%) D.III Keperawatan dan 1 orang $(5,26 \%)$ berijazah SPK. Data ini memberikan gambaran bahwa kualitas tenaga keperawatan masih didominasi oleh tenaga madya profesional pemula yang apabila dihadapkan pada berbagai kebutuhan perawatan pasien tentunya akan mengalami kesulitan karena keterbatasan kemampuan, pengetahuan dan analisis kasus.

Dengan demikian, untuk mengatasi hal diatas perlu dilakukan langkah - langkah yang positif khususnya komunikasi terapeutik dalam pemberian pelayanan keperawatan yang mencakup perawatan fisik (pemenuhan kebutuhan fisik), perawatan psikologi (pemenuhan kebutuhan psikologi), perawatan sosial (pemenuhan kebutuhan sosial), dan perawatan spiritual (pemenuhan kebutuhan spiritual) sesuai dengan konsep keperawatan holistik. Pemberian pelayanan keperawatan yang terintegrasi (fisik, psikologi, sosial spiritual dan edukasi) serta dilaksanakan sesuai dengan standar diharapkan stress hospitalisasi pada anak dapat diminimalisir.

\section{METODE}

Penelitian ini termasuk jenis penelitian survey analitik yaitu desain cross-sectional study. Populasi dalam penelitian ini adalah semua pasien yang dirawat pada saat penelitian berlangsung. Berdasarkan rata - rata jumlah pasien rawat inap anak per bulan selama tiga bulan terakhir yaitu : bulan Januari, Februari, Maret, 2017 di Ruang Mawar RSU Bahteramas sebesar 128 pasien usia toddler (1 - 3 tahun) dengan rata - rata kunjungan 43 pasien / bulan. Teknik pengambilan sampel dilakukan dengan stratified random sampling, jumlah sampel dalam penelitian ini berjumlah 39 pasien. Variabel dalam penelitian ini adalah fase pra interaksi, perkenalan, orientasi, tahap kerja, dan terminasi, dan variabel terikat adalah stress hospitalisasi. Instrumen dalam penelitian ini adalah lembar kuesioner. Analisis data dengan analisis univariat dan analisis bivariat untuk menguji hubungan fase pra interaksi, perkenalan, orientasi, tahap kerja, dan terminasi dengan stress hospitalisasi dengan uji chi-square pada taraf kepercayaan $95 \%$.

\section{HASIL DAN PEMBAHASAN}

Analisis bivariat menggunakan uji statistik fisher's exact test pada tingkat kepercayaan 95\% ( $\alpha$ $=0,05$ ) disajikan pada tabel 1, 2, 3, 4 dan 5 sebagai berikut : 
Jurnal Ilmiah Mahasiswa Kesehatan Masyarakat Vol. 5/No.4/Oktober 2020; ISSN:2502-731X

Tabel 1. Hubungan Fase Pra Interaksi dengan Stres Hospitalisasi Pada Anak Usia Toddler di Ruang Mawar Lantai 2 RSU Bahteramas Provinsi Sulawesi Tenggara

\begin{tabular}{|c|c|c|c|c|c|c|c|c|}
\hline \multirow{3}{*}{ Pra Interaksi } & \multicolumn{4}{|c|}{ Stress Hospitalisasi } & \multicolumn{2}{|c|}{ Total } & \multirow[t]{2}{*}{ Pvalue } & \multirow[t]{2}{*}{ phi } \\
\hline & \multicolumn{2}{|c|}{$\begin{array}{c}\text { Tidak mengalami stres } \\
\text { hospitalisasi }\end{array}$} & \multicolumn{2}{|c|}{$\begin{array}{c}\text { Mengalami stres } \\
\text { hospitalisasi }\end{array}$} & & & & \\
\hline & $n$ & $\%$ & $\mathrm{n}$ & $\%$ & $\mathrm{n}$ & $\%$ & & \\
\hline Baik & 21 & 100 & 0 & 0 & 21 & 100 & & \\
\hline Kurang baik & 12 & 66,7 & 6 & 33,3 & 18 & 100 & 0,006 & 0,461 \\
\hline Total & 33 & 84,6 & 6 & 15,4 & 39 & 100 & & \\
\hline
\end{tabular}

Sumber : Data Primer, 2017

Tabel 2. Hubungan Fase Perkenalan dengan Stres Hospitalisasi Pada Anak Usia Toddler di Ruang Mawar Lantai 2 RSU Bahteramas Provinsi Sulawesi Tenggara

\begin{tabular}{|c|c|c|c|c|c|c|c|c|}
\hline \multirow{3}{*}{ Perkenalan } & \multicolumn{4}{|c|}{ Stress Hospitalisasi } & \multicolumn{2}{|c|}{ Total } & \multirow{3}{*}{ Pvalue } & \multirow{2}{*}{ phi } \\
\hline & \multicolumn{2}{|c|}{$\begin{array}{c}\text { Tidak mengalami stres } \\
\text { hospitalisasi }\end{array}$} & \multicolumn{2}{|c|}{$\begin{array}{c}\text { Mengalami stres } \\
\text { hospitalisasi }\end{array}$} & \multirow[b]{2}{*}{$\mathrm{n}$} & \multirow[b]{2}{*}{$\%$} & & \\
\hline & $\mathrm{n}$ & $\%$ & $\mathrm{n}$ & $\%$ & & & & \\
\hline Baik & 26 & 92,9 & 2 & 7,1 & 28 & 100 & & \\
\hline Kurang baik & 7 & 63,6 & 4 & 36,4 & 11 & 100 & 0,042 & 0,364 \\
\hline Total & 33 & 84,6 & 6 & 15,4 & 39 & 100 & & \\
\hline
\end{tabular}

Sumber : Data Primer, 2017

Tabel 3. Hubungan Fase Orientasi Dengan Stres Hospitalisasi Pada Anak Usia Toddler di Ruang Mawar Lantai 2 RSU Bahteramas Provinsi Sulawesi Tenggara

\begin{tabular}{|c|c|c|c|c|c|c|c|c|}
\hline \multirow{3}{*}{ Orientasi } & \multicolumn{4}{|c|}{ Stress Hospitalisasi } & & & \multirow{3}{*}{ Pvalue } & \multirow{3}{*}{ phi } \\
\hline & \multicolumn{2}{|c|}{$\begin{array}{c}\text { Tidak mengalami stres } \\
\text { hospitalisasi }\end{array}$} & \multicolumn{2}{|c|}{$\begin{array}{c}\text { Mengalami stres } \\
\text { hospitalisasi }\end{array}$} & \multicolumn{2}{|c|}{ Total } & & \\
\hline & $\mathrm{n}$ & $\%$ & $\mathrm{n}$ & $\%$ & $\mathrm{n}$ & $\%$ & & \\
\hline Baik & 12 & 66,7 & 6 & 33,3 & 18 & 100 & & \\
\hline Kurang baik & 21 & 100 & 0 & 0 & 21 & 100 & 0,006 & - \\
\hline Total & 33 & 84,6 & 6 & 15,4 & 39 & 100 & & \\
\hline
\end{tabular}

Sumber : Data Primer, 2017

Tabel 4. Hubungan Fase Kerja dengan Stres Hospitalisasi Pada Anak Usia Toddler di Ruang Mawar Lantai 2 RSU Bahteramas Provinsi Sulawesi Tenggara

\begin{tabular}{|c|c|c|c|c|c|c|c|c|}
\hline \multirow{3}{*}{ Kerja } & \multicolumn{4}{|c|}{ Stress Hospitalisasi } & \multicolumn{2}{|c|}{ Total } & \multirow[t]{2}{*}{ PValue } & \multirow[t]{2}{*}{ phi } \\
\hline & \multicolumn{2}{|c|}{$\begin{array}{c}\text { Tidak mengalami stres } \\
\text { hospitalisasi }\end{array}$} & \multicolumn{2}{|c|}{$\begin{array}{c}\text { Mengalami stres } \\
\text { hospitalisasi }\end{array}$} & & & & \\
\hline & $\mathrm{n}$ & $\%$ & $\mathrm{n}$ & $\%$ & $\mathrm{n}$ & $\%$ & & \\
\hline Baik & 19 & 100 & 0 & 0 & 19 & 100 & & \\
\hline Kurang baik & 14 & 70 & 6 & 30 & 20 & 100 & 0,020 & 0,416 \\
\hline Total & 33 & 84,6 & 6 & 15,4 & 39 & 100 & & \\
\hline
\end{tabular}

Sumber : Data Primer, 2017 
Tabel 5. Hubungan Fase Terminasi dengan Stres Hospitalisasi Pada Anak Usia Toddler di Ruang Mawar Lantai 2 RSU Bahteramas Provinsi Sulawesi Tenggara

\begin{tabular}{|c|c|c|c|c|c|c|c|c|}
\hline \multirow{3}{*}{ Terminasi } & \multicolumn{4}{|c|}{ Stress Hospitalisasi } & \multicolumn{2}{|c|}{ Total } & \multirow{3}{*}{ Pvalue } & \multirow{2}{*}{ phi } \\
\hline & \multicolumn{2}{|c|}{$\begin{array}{c}\text { Tidak mengalami stres } \\
\text { hospitalisasi }\end{array}$} & \multicolumn{2}{|c|}{$\begin{array}{c}\text { Mengalami stres } \\
\text { hospitalisasi }\end{array}$} & & & & \\
\hline & $\mathrm{n}$ & $\%$ & $\mathrm{n}$ & $\%$ & $\mathrm{~N}$ & $\%$ & & \\
\hline Baik & 16 & 72,7 & 6 & 27,3 & 22 & 100 & \multirow{3}{*}{0,027} & \multirow{3}{*}{0,375} \\
\hline Kurang baik & 17 & 100 & 0 & 0 & 17 & 100 & & \\
\hline Total & 33 & 84,6 & 6 & 15,4 & 39 & 100 & & \\
\hline
\end{tabular}

Sumber : Data Primer, 2017

Hasil analisis dengan fisher's exact test dengan tingkat kepercayaan $95 \%$ atau $\alpha$ 0,05, menunjukan bahwa fase pra interaksi dengan stress hospitalisasi dengan $p_{\text {value }}=0,006$, fase perkenalan dengan stres hospitalisasi dengan $p_{\text {value }}=0,042$, fase orientasi dengan stres hospitalisasi dengan $p_{\text {value }}=0,006$, fase kerja dengan stres hospitalisasi dengan $p_{\text {value }}=0,020$, fase terminasi dengan stres hospitalisasi dengan $p_{\text {value }}=0,027$. Hasil analisis tersebut disimpulkan bahwa ada hubungan antara fase pra interaksi, fase perkenalan, fase orientasi, fase kerja, dan fase terminasi dengan stress hospitalisasi pada anak usia toddler di RSU Bahteramas Provinsi Sulawesi Tenggara.

\section{Fase pra interaksi dengan stress hospitalisasi}

Pra Interaksi merupakan masa persiapan sebelum berhubungan dan berkomunikasi dengan pasien. Perawat diharapkan tidak memiliki prasangka buruk kepada pasien karena akan mengganggu dalam membina hubungan dan saling percaya. Keadaan ini menunjukkan bahwa fase pra interaksi merupakan kewajiban yang harus dijalankan dalam melaksanakan tugasnya sehingga secara tidak langsung memberikan kontribusi terhadap stress hospitalisasi pada pasien anak yang dirawat. Pra Interaksi dimulai sebelum kontrak pertama dengan klien. Perawat mengumpulkan data tentang klien, mengeksplorasi perasaan, fantasi dan ketakutan diri dan membuat rencana pertemuan dengan klien.

Perawat memegang faktor kunci keberhasilan pelayanan rumah sakit, dalam bekerja perawatlah yang paling banyak dan paling sering berhubungan dengan pasien maupun keluarganya sehingga memungkinkan perawat sering berkomunikasi dengan pasien maupun keluargannya. Kemampuan perawat dalam berkomunikasi dengan pasien merupakan hal yang mendasar dan penting dalam penyelenggaraan proses keperawatan. Penerapan komunikasi terapeutik merupakan media dalam mengembangkan hubungan antara perawat dan pasien maupun keluargnya ${ }^{5}$.

Komunikasi terapeutik merupakan komunikasi yang memiliki makna terapeutik bagi pasien dan dilakukan oleh perawat untuk membantu pasien mencapai kondisi yang adaptif dan positif. Perawat yang memiliki keterampilan komunikasi terapeutik tidak saja akan mudah menjalani hubungan rasa percaya dengan pasien, mencegah terjadinya masalah dalam memberi keputusan professional keperawatan serta citra dari rumah sakit.

Fase perkenalan dengan stress hospitalisasi

Perkenalan merupakan kegiatan yang pertama kali dilakukan oleh perawat terhadap pasiennya yang baru memasuki rumah sakit. Hubungan yang baik dari perawat tentunya akan memberikan dampak yang baik untuk mengurangi stress pada anak yang dirawat di rumah sakit. Perawat menunjukan keramahan dengan senyuman dalam menjawab pertanyaan pasien dan menghargai pasien. Fase perkenalan yang dimaksud seperti : perawat dan pasien mulai mengembangkan hubungan komunikasi interpersonal yaitu dengan memberikan salam, senyum, memberikan keramahtamahan pada pasien, memperkenalkan diri, menanyakan nama pasien dan menanyakan keluhan pasien, dan lainlain. Hal ini ditunjang pula dengan sumber daya perawat di ruang Mawar yang hampir seluruhnya $(81,82 \%)$ memiliki latar belakang pendidikan D3 Keperawatan yang dari segi konsep kurikulum pendidikan berorientasi pada keterampilan atau praktikum klinik keperawatan sehingga keterampilan yang dimiliki cukup untuk melakukan tindakan keperawatan baik yang bersifat kesehatan klinik keperawatan maupun kesehatan komunitas sosial masyarakat 


\section{Fase orientasi dengan stress hospitalisasi}

Tahap orientasi dilaksanakan pada awal pertemuan sampai seterusnya selama pasien berada di rumah sakit. Tujuan tahap orientasi adalah memeriksa keadaan pasien, menvalidasi keakuratan data, rencana yang telah dibuat dengan keadaan pasien saat itu, dan mengevaluasi hasil tindakan. Pada tahap ini sangat diperlukan sentuhan hangat dari perawat dan perasaan simpati dan empati agar pasien merasa tenang dan merasa dihargai.

\section{Fase kerja dengan stress hospitalisasi}

Fase kerja merupakan inti hubungan perawat dan pasien yang terkait erat dengan pelaksanaan komunikasi interpersonal. Perawat memfokuskan arah pembicaraan pada masalah khusus yaitu tentang keadaan pasien dan keluhan-keluhan pasien. Pada tahap kerja dalam komunikasi terapeutik, kegiatan yang dilakukan adalah memberi kesempatan pada klien untuk bertanya, menanyakan keluhan utama, memulai kegiatan dengan cara yang baik, melakukan kegiatan sesuai dengan rencana. Perawat memenuhi kebutuhan dan mengembangkan pola-pola adaptif klien serta memfokuskan arah pembicaraan pada masalah khusus yaitu tentang keadaan pasien dan keluhankeluhan pasien.

Selain itu hendaknya perawat juga melakukan komunikasi interpersonal yaitu dengan seringnya berkomunikasi dengan pasien, mendengarkan keluhan pasien, memberikan semangat dan dorongan pada pasien, serta memberikan anjuran pada pasien untuk makan, minum obat yang teratur dan istirahat teratur, dengan tujuan adanya penyembuhan.

\section{Fase terminasi dengan stress hospitalisasi}

Terminasi merupakan tahap akhir dalam komunikasi interpersonal dan akhir dari pertemuan antara perawat dan pasien. Tahap terminasi dalam komunikasi terapeutik kegitan yang dilakukan oleh perawat adalah menyimpulkan hasil wawancara, tindak lanjut dengan klien, melakukan kontrak (waktu, tempat, dan topik), mengakhiri wawancara dengan cara yang baik ${ }^{6}$.

Fase terminasi ini merupakan terminasi yang terjadi jika pasien akan keluar atau pulang dari rumah sakit. Dalam terminasi ini hendaknya perawat tetap memberikan semangat dan mengingatkan untuk tetap menjaga dan meningkatkan kesehatan pasien sehingga komunikasi interpersonal antara perawat dan pasien terjalin dengan baik. Pada tahap ini akan terlihat apakah pasien merasa senang dan puas dengan perlakuan atau pelayanan yang diberikan perawat kepada pasien.

Perawat memegang faktor kunci keberhasilan pelayanan rumah sakit, dalam bekerja perawatlah yang paling banyak dan paling sering berhubungan dengan pasien maupun keluarganya sehingga memungkinkan perawat sering berkomunikasi dengan pasien maupun keluargannya. Kemampuan perawat dalam berkomunikasi dengan pasien merupakan hal yang mendasar dan penting dalam penyelenggaraan proses keperawatan. Penerapan komunikasi terapeutik merupakan media dalam mengembangkan hubungan antara perawat dan pasien maupun keluargnya.

\section{PENUTUP}

Fase pra interaksi, fase perkenalan, fase orientasi, fase kerja, dan fase terminasi mempunyai hubungan yang signifikan dengan dengan stress hospitalisasi pada anak usia toddler di Ruang Mawar Lantai 2 RSU Bahteramas Provinsi Sulawesi Tenggara. Peningkatan kualitas pelayanan untuk meningkatkan kepuasan pasien rawat inap khususnya terkait komunikasi terapeutik dalam memberikan pelayanan kepada pasien. serta meningkatkan pelaksanaan komunikasi sesuai tahapan komunikasi terapeutik dalam memberikan pelayanan keperawatan kepada pasien.

\section{DAFTAR PUSTAKA}

1. Makmur, 2011. Komunikasi Terhadap Pasien di Rumah Sakit. Http:.medical.co.id. Diakses tanggal 29 April 2017.

2. Hamid. 2008. Perencanaan Kesehatan Untuk Meningkatkan Efektifitas Manajemen, Gajah Mada University Press: Yogyakarta.

3. Wong. D. L dkk. 2008. Buku Ajar Keperawatan Pediatrik Edisi 6 Volume 2. Jakarta : EGC.

4. Rohmani. 2009. Pendekatan Perawat dalam Mengatasi Kecemasan dan ketakutan pada Anak Usia Sekolah di Ruang Lukman Rumah Sakit Roemani Muhammadiyah Semarang. Skripsi. Semarang: Program studi ilmu keperawatan Fakultas IImu Keperawatan dan kesehatan Universitas Muhammadiyah Semarang.

5. Purwanto. 2004. Pengantar Perilaku Manusia Untuk Keperawatan ,EGC, Jakarta.

6. Stuart dan Sundeen. 2005. Principle and Practice of Psychiartric Nursing, Sixth -Edition. Toronto; CV Masby. Co. 1998.http:..nersing medical.co.id. Diakses Tanggal 27 April 2017. 